\title{
Students' Thinking Processes Connecting Quantities in Solving Covariation Mathematical Problems in High School Students of Indonesia
}

\author{
Syarifuddin Syarifuddin* \\ Department of Mathematics Education, STKIP Bima, Bima, Indonesia \\ ORCID: 0000-0003-3352-0910
}

Toto Nusantara

Department of Mathematics Education, Universitas Negeri Malang, Malang, Indonesia ORCID: 0000-0003-1116-9023

\author{
Abd. Qohar \\ Department of Mathematics Education, Universitas Negeri Malang, Malang, Indonesia \\ ORCID: 0000-0001-8532-102X
}

\section{Makbul Muksar}

Department of Mathematics Education, Universitas Negeri Malang, Malang, Indonesia ORCID: 0000-0002-5829-8650

\begin{tabular}{ll}
\hline \hline Article history & The purpose of this study was to describe students' thinking processes \\
Received: & in relating quantities to the problem of covariation in the process of \\
& solving mathematical problems. This study used a descriptive \\
Received in revised form: & exploratory approach within the scope of qualitative research involving \\
12.05 .2020 & 87 students as prospective subjects from three different high schools. \\
Accepted: & The schools were chosen from three different areas; where two schools \\
28.05 .2020 & were on Sumbawa island namely in Bima district and Bima town. The \\
Key words: & subject described was chosen by giving assignments related to the \\
Connecting quantities; & covariation problem. Data obtained from the answer sheets from the \\
covariation problem solving; & subjects while doing think aloud, the results of task-based interviews, \\
APOS theory; & and field notes. Supporting equipment for video and audio recording \\
& was used to take data of think aloud and interview. Data analysis was \\
& conducted retrospectively by combining answer sheets, think aloud, \\
interview results and field notes with reference to APOS theory. The & results obtained from students thinking processes in connecting the \\
& quantities of covariation were two, namely Connecting Quantity by \\
direct analytic and equation analytic. In general, it was found that & students connected quantities in covariation problem solving by linking \\
changing-quantity along with the changes in other quantities internally \\
or externally through mathematical analysis to form new quantities \\
based on quantitative operations.
\end{tabular}

\footnotetext{
*Correspondency: syarifuddin_mat@stkipbima.ac.id
} 


\section{Introduction}

One of mathematics learning standards (NCTM, 2000) is reasoning. The purpose of mathematics subject is to enhance the students to have reasoning ability. Reasoning according to Krulik, Rudnick, \& Milou (2003) is part of the thinking process, but often thinking and reasoning are applied synonymously. According to Bybee (1982), reasoning is systematic and it involves logical process. Then according to Brown (2007), reasoning is logical and abstract thinking in the freedom of using the contents of the rules used.

Reasoning is a special type of thinking to draw conclusions or make a new statement based on known statements (Copi, 1978). In the process of drawing conclusions, Carroll (1993) divides three main reasoning abilities, namely sequential (deductive), inductive, and quantitative. Quantitative Reasoning is a form of reasoning that is very useful in learning mathematics because through this reasoning students can develop their abilities through the quantitative information provided. Quantitative reasoning has a focus on quantity and quantity relationships, which means approaching mathematical topics from certain mathematical attitudes that emphasize activities such as measurement, conceptualization of quantities, and establishing mathematical relationships (Thompson, 1993). This is supported by the opinion of (Ramful, 2009; Weber et al., 2014) who say that quantitative reasoning is the basis supporting students in modelling mathematical phenomena because it provides a means for students to create relationships between quantities, create new quantities, and make conclusions with quantities.

The quantity in this case (Kaput, 1995; Smith \& Thompson, 2007; Thompson, 1994) is a person's conception of the quality of the object or phenomenon, unit or dimension that are appropriate, and a process for assigning a numerical value to quality. Steffe \& Olive (2010) argue that quantity is a person's concept of an object or phenomenon "which can be compared". Therefore, it can be concluded that quantity is a person's conception of an object (quality, unit, and corresponding dimension) that can be measured.

In this study, the quantity connected is a covariation quantity. Covariation according to Slavit (1997) is defined as the relationship between changes in quantity. According to Johnson (2012), there are three perspectives of covariation. The three perspectives on covariation highlight the difference on the way a person can feel the relationship between the quantity of covariation involved in a particular situation. The first covariation is static covariation (Confrey \& Smith, 1995), and the next two covariations are dynamic covariation namely discrete dynamic covariation (Clement, 1989) and continuous dynamic covariation (Saldanha \& Thompson, 1998).

The relationship of quantities to the problem of covariation has been done on previous studies by several researchers (Carlson, 1998; Carlson et al., 2002; Köklü, 2007; Syarifuddin et al., 2019b) by concluding that not many high school students and college students can describe dynamic functional situations and connect covariation strength. Other research on quantitative reasoning conducted by Ellis (2007) investigating student generalization activities and reasoning about linear relationships. Teaching experiments and observations were also carried out on seven high school students about two quantitative situations, the first involving the gear ratios and the second involving speed. During the experiment, students create a ratio that appears as a quantity in their understanding, which means that they use two directly measured quantities, such as distance and time, to create a third quantity (speed). Then Moore \& Carlson (2012) conducted on nine students (aged between 18 to 25 years) is to look at mental activity in visualizing situations and building relevant quantitative relationships before 
determining formulas and graphs. Another study conducted by Moore (2014), a teaching experiment to see students' mental actions (MA) in exploring angular and trigonometric functions.

Quantitative reasoning (Dwyer et al., 2003; Moore, 2014; Thompson, 1993) is the ability to analyze quantitative information in looking at problem situation as a quantity network and quantity relation to form a series of quantitative operations (skills or procedures) in determining a solution. In this case, quantitative reasoning becomes the basis in the problem solving process. Solving the problem of covariation is conducted by paying attention to the six steps in quantitative reasoning (Dwyer et al., 2003). The six steps are understanding information, determining mathematical methods, the process of solving problems, communicating quantitative information, estimating and checking the feasibility of answers, interpreting and drawing conclusions from quantitative information.

\section{Thinking Process of Students Connecting Quantities through the steps in APOS Theory}

The problem solving process is a part of quantitative reasoning. Students with mathematical self-efficacy have good problem solving skills (Sümen \& Çalış1c1, 2016). In this case, the reasoning process will be investigated through the stages of APOS theory. As explained by Burns-Childers \& Vidakovic (2018), to investigate mental construct arising in students' reasoning on a problem can use APOS theory. APOS (Arnon et al, 2014) is a mental structure constructed by students in developing an understanding of mathematical concepts. APOS theory is a constructivist framework (reflective abstraction) emphasizing the construction of mental structures (Dubinsky, 1991). In the mental structure of this theory, it consists of mental constructs (Action, Process, Object, and Schema) and mental mechanisms (interiorization, encapsulation, de-encapsulation, coordination, and reversal) (Arnon et al, 2014; Dubinsky, 1991; Parraguez \& Oktaç, 2010).

APOS theory and its application to teaching practice are based on assumptions on mathematical knowledge and hypotheses on learning. APOS theory can be used as an analytical tool to describe the development of individual schema on a particular mathematical topic which is the totality of knowledge related to that topic (Dubinsky, 2001; Dubinsky \& Mcdonald, 2011). It says that APOS Theory describes the action that is interiorized as a process. Then the process is encapsulated into an object, and vice versa an object can be deencapsulated to return to the process stage. The range of actions, processes and objects form a scheme.

APOS Theory application in research begins with the stage when students carry out the mechanism of interiorization by reading and understanding information through paying attention to the problem as a whole part to connect quantities. At the process stage, students use a coordination mechanism to determine the appropriate mathematical problem solving method to solve the problem. At this process, students then coordinate and reverse mechanisms by solving problems using arithmetic, algebra, or geometry. At the object stage, students do encapsulation by communicating quantitative information, estimating and checking eligibility through encapsulating and de-encapsulating to connect quantities by coordinating quantities values. While at the scheme stage, students interpret quantitative information and draw conclusions. 


\section{Problem of Research}

From the citation of the theory and some of the results of the research described above, it reveals the difficulty of high school and college students in relating quantities to the problem of covariation. Then they reveal the success of students in visualizing the quantity relationship graph in the form of a Cartesian chart. Whereas this study was going to describe students' thinking processes in expressing the problem solving process carried out by high school students, visualizing the problem solving into a Cartesian chart and concluding mathematical concepts from the quantity produced. Therefore, the research problem arised was how did students' thinking processes relate quantity in the process of solving covariation problems and how did students obtain mathematical concepts from the problem solving process and the resulting graph visualization?

\section{Method}

This research revealed students' thinking processes in building quantitative reasoning in solving covariation problems. This research used a descriptive exploratory approach within the scope of qualitative research. The characteristics of qualitative research were natural settings, researchers as key instruments, multiple sources of data, inductive data analysis, emergent design, and holistic accounts (Creswell, 2012).

\section{Participants}

This research was conducted on high school students from three different schools in Indonesia. The three schools were chosen from different islands and tribes, with the aim to see a comparison of the thinking processes produced by students who had different characters. One school was chosen from the island of Java in Malang town and two schools selected from the island of Sumbawa, namely in Bima district and Bima town. For research purpose, each school was taken one class each by coordinating with the mathematics teacher in determining the class. Provisions for class determination included not interfering with the learning process that was taking place and classes where students had the ability to communicate verbally and in writing in order to be able to conduct a process of thinking aloud and task-based interviews. The students involved in the research as shown in Table 1.

Table 1. Data of students who participate as subject candidate

\begin{tabular}{cccc}
\hline & Region & The number of class & The number of student \\
\hline & Malang City & 1 class & 32 \\
& Bima District & 1 class & 28 \\
& Bima Town & 1 class & 27 \\
\hline Total & & & 87 \\
\hline
\end{tabular}

\section{Data Collection}

The data in this study were obtained from students' work in the form of written descriptions on answer sheets, recorded think aloud in the form of video and audio, recorded interviews between researchers and selected subjects in the form of video and audio, and field notes in the form of research notes that occurred during the process research. Think Aloud was used to examine the flow of problem solving, while interviews were used to explore the process that required clarity from the answer sheet and think aloud. Data on students' work were collected directly by researcher by distributing question and answer sheets provided. While think aloud recordings and interviews were conducted by researcher using video 
recording equipment and audio recorder. The instrument used to collect data is shown in Figure 1.

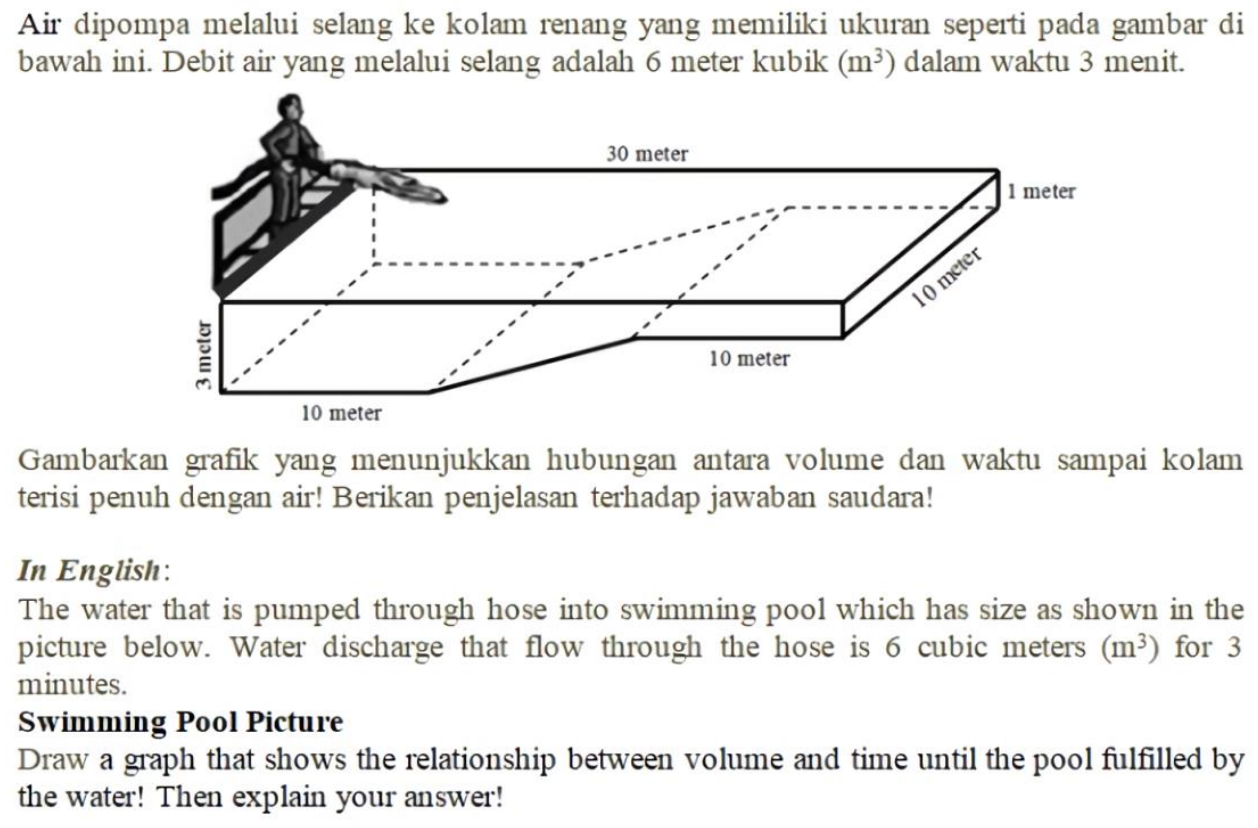

Air dipompa melalui selang ke kolam renang yang memiliki ukuran seperti pada gambar di bawah ini. Debit air yang melalui selang adalah 6 meter kubik $\left(\mathrm{m}^{3}\right)$ dalam waktu 3 menit.

Gambarkan grafik yang menunjukkan hubungan antara volume dan waktu sampai kolam terisi penuh dengan air! Berikan penjelasan terhadap jawaban saudara!

In English:

The water that is pumped through hose into swimming pool which has size as shown in the picture below. Water discharge that flow through the hose is 6 cubic meters $\left(\mathrm{m}^{3}\right)$ for 3 minutes.

\section{Swimming Pool Picture}

Draw a graph that shows the relationship between volume and time until the pool fulfilled by the water! Then explain your answer!

Figure 1. Covariation problem solving instrument

\section{Data Analysis}

Data obtained from student work, think aloud records, interview records, and field notes were then analyzed using a retrospective analysis that combined several data sources. To distinguish the thinking process carried out by each subject, analysis was conducted using comparative analysis (Corbin \& Strauss, 2012). This comparative analysis was carried out by looking at the process at the APOS stage, by compiling the coding to distinguish each stage, as in Table 2. This analysis was conducted by describing the stages carried out by the subjects in accordance with the stages of the APOS Theory, those which was described simultaneously with the problem-solving steps in quantitative reasoning. From the analysis carried out then the research conclusions were drawn from the research findings.

Table 2. APOS stage coding in relating quantities

\begin{tabular}{cccc}
\hline & Term & Code & Term \\
\hline & Volume quantity & - & Processes \\
\hline & Time quantity & - & Object \\
\hline & Length quantity & - & Scema \\
\hline & Width quantity & Inter-Act & Interiorization Action \\
\hline & Height quantity & Coord & Coordination \\
\hline
\end{tabular}




\section{Procedure}

The research process was carried out in three stages. The first stage was research preparation, when the researcher began to compile a research plan that examined the theories and the results of previous research in supporting the research topic, compiling the research instruments, and validating the instruments with experts. Furthermore, it was coordinated with the schools where the study was conducted. In the second stage, the subjects were selected from 87 students to do the assignment while doing think aloud and interviewing. At this stage, students were given the task to solve the covariation problem within 45 minutes. Students' work in the form of answer sheets was then corrected to get the subject that gave the correct answer. The correct answer was then categorized based on different problem solving procedures. After obtaining the subjects with different categories, then third stage was conducted, which was recording the subjects doing think aloud. The results, obtained from the recording, then were examined to observe the problem solving procedure and recorded interviews with the subjects.

\section{Results}

The process of selecting subjects made from student work revealed 40 students who solved problems with the correct processes and results. Thus, the subjects in this study were 40 subjects, with details of 17 subjects from the city of Malang, 10 subjects from the Bima district, and 13 subjects from Bima town. Based on students 'answers, the thinking processes of students who gave correct answers and those who answered incorrectly from the three schools did not differ significantly, so it was assumed that the level of students' thinking processes was the same.

Broadly speaking, students' thinking processes in linking quantities in covariation problem solving can be divided into two categories, so that the subject presented was taken one subject each representing the same thinking process from a different category. In the first category, subject 1 was hereinafter referred to as $\mathrm{S} 1$, and the second category subject 2 was hereinafter referred to as $\mathrm{S} 2$.

\section{First category (S1) data analysis and presentation}

S1 data presented was describing the structure of thinking in completing the task of solving covariation problems based on the stages of quantitative reasoning. The stages were understanding information, determining mathematical methods, the process of solving problems, communicating quantitative information, estimating and checking the feasibility of answers, interpreting and drawing conclusions from quantitative information. From the work, think aloud record, interview record, and field notes from S1 were simultaneously analyzed and known at the APOS theory stage (Action, Process, Object, and Schema).

In the action phase, $\mathrm{S} 1$ began to do the task by reading and understanding the information provided in full context. At this stage, S1 paid attention to the commands in the task, then planned the steps taken to complete the task. S1 paid attention to the shape of the pool image and identified the quantities in the pool, namely the length of the pool, the width of the pool, and the height of the pool. S1 could not calculate the pool volume directly, but partition it into several geometry to make it easier to get the pool volume until it was fully charged. The pool was divided into three parts consisting of a beam-shaped geometry, a trapezoidal prismshaped geometry, and a beam-shaped geometry. Then each geometry was identified by 
quantities on its sides. The pool-parting process is a coordination mental mechanism on process stage. This can be seen from the work of S1 on the answer sheet in planning to solve the problem as shown in Figure 2.

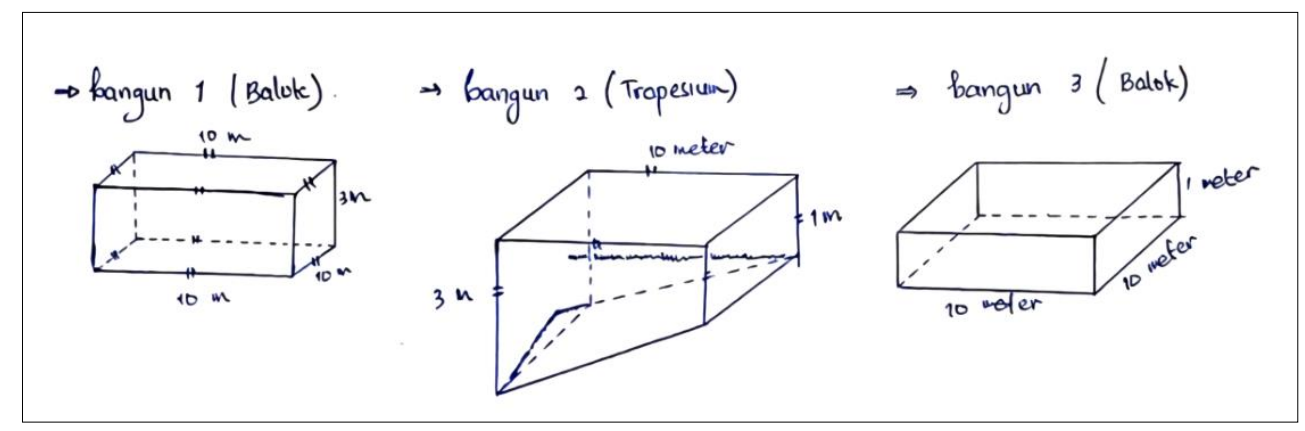

Figure 2. S1 Work Outcomes in planning problem solving

This was reinforced from the results of think aloud conducted by S1 as in the following quote.

$\mathrm{S} 1 \quad$ : The first geometry is a beam. This second geometry is a lying trapezoidal geometry. Then the third geometry is a beam.

When asked about the information, S1 used to solve the problem through the interview process, S1 said that there were two beams and one trapezoidal prism in the middle. This was shown in the following interview excerpts from researchers and S1.

$\mathrm{R} \quad$ : Then what information can you use to solve this problem?

$\mathrm{S} 1 \quad$ : The information that I used is a picture of the pond, first divided there are some geometry in it. There are 2 beams and 1 trapezoid in the middle.

Still in the stage of understanding information, in each form of space that was separated as in Figure 2, S1 identified each of the quantities existing in each geometry. In the first geometry (beam), S1 wrote length $(l)=10$ meters, width $(w)=10$ meters, and height $(h)=3$ meters. In the second geometry (trapezoidal prism), the length of the facing side was the bottom side $(a)$ $=3$ meters and the top side $(b)=1$ meters, and height $(h)=10$ meters. Then the quantities component in the third geometry (beam) with length $(l)=10$ meters, width $(w)=10$ meters, and height $(h)=1$ meter.

The next stage of S1 determined the mathematical method to solve the problem. In this case,

The next stage is process stage, $\mathrm{S} 1$ was doing reversal mechanism to call back mathematical method solving the problem. In this case, S1 was looking for the pool volume by finding each of the separated building volumes of geometry, and then the volumes were added up. This can be seen from the following think aloud S1 quote.

S1 : Pool volume is equal to volume 1 building plus volume 2 building plus volume 3 building.

This was reinforced by the work of S1 in determining mathematical methods for solving problems as shown in Figure 3. 


$$
\text { Volume kolain : Volume bangun } 1+v \text {. Bangun } 2+v \text {. bangun } 3
$$

In English:

Pool Volume $=$ Volume of Geometry $1 \times$ Volume of Geometry $2 \times$ Volume of Geometry 3

Figure 3. The work of $\mathrm{S} 1$ in determining mathematical methods

In the reversal process stage, S1 was calling back the mathematical method to find the pool volume until it was fully filled by finding the volume of each part of the pool that had been divided into three forms, then the results were added to get the pool volume in full context. The first and third geometric volumes could be found with the formula $V=l \times w \times h$, and the second geometric volume was found with the formula $V=((a+b) / 2 \times h) \times h$. The next form of interiorization of action was to substitute the quantity of each geometry into the volume formula, so that the first building volume was obtained $V=10 \times 10 \times 3=300 \mathrm{~m}^{3}$, the volume of the second geometry was $V=((3+1) / 2 \times 10) \times 10=200 \mathrm{~m}^{3}$, and the volume of the third geometry was $V=10 \times 10 \times 1=100 \mathrm{~m}^{3}$. When looking for this volume, there was coordination between the three geometries because they were in one unit building (pool). While the reversal process occurred when S1 used the same formula in finding the volume of geometry, namely $V=L_{\text {base }} \times h$. The process of solving the problem in finding a pool volume carried out by $\mathrm{S} 1$ is shown in Figure 4.

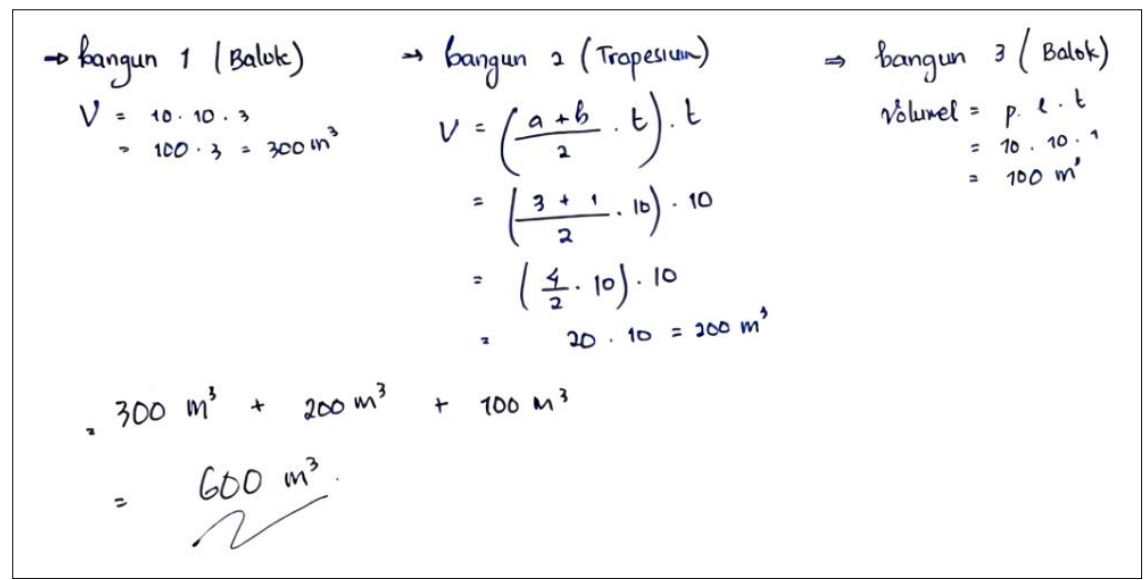

Figure 4. The work of S1 in finding pool volume

This was reinforced by the results of think aloud conducted by S1 as in the following quote.

$\mathrm{S} 1 \quad$ : The volume is equal to $l \times w \times h, l=10$ meters, $w=10$ meters, and $h=3$ meters, so this is equal to $10 \times 10 \times 3=300 \mathrm{~m}^{3}$. The volume of the first geometry is already gained. Then second geometry is a trapezoidal prism of a lying structure. Its height is 1 meter, then the length is of 10 meters, then the base is 3 meters, this is the volume of the trapezoidal prism, $V=((a+b) / 2 \times$ h) $\times h=((3+1) / 2 \times 10) \times 10=(4 / 2 \times 10) \times 10=20 \times 10$. Then the third trigonometry. Its height is 1 meter, its height is 10 meters, then its width is 10 meters, so the volume $=l \times w \times h=10 \times 10 \times 1=100 \mathrm{~m}^{3}$.

At the next process stage, S1 was doing coordination by adding up the volume of the three existing structures in the pool. $V_{\text {pool }}=V_{1}+V_{2}+V_{3}=300 \mathrm{~m}^{3}+200 \mathrm{~m}^{3}+100 \mathrm{~m}^{3}=600 \mathrm{~m}^{3}$, as shown in the summation results in Figure 4. After obtaining the fully filled pool volume, S1 performed the de-encapsulation process to determine the coordinate points in drawing graphs of the relationship between volume and time. In this case, S1 did the process of determining 
the coordinates of the point by directly mentioning the coordinates without doing calculations using equations or analysis conducted by $\mathrm{S} 1$ occurred in the internal mind. When the quantity of time $t=3$ minutes, the pool would be filled with $V=6 \mathrm{~m}^{3}$; when $h=6$ minutes then the pool would be filled with $V=12 \mathrm{~m}^{3}$; when $t=9$ minutes then the pool would be filled with $V$ $=18 \mathrm{~m}^{3}$; then when $t=12$ minutes then the pool would be filled with $V=24 \mathrm{~m}^{3}$, and so on until the time to fill the pool full with $t=300$ minutes then the pool would be filled with $V=$ $600 \mathrm{~m}^{3}$.

After determining the coordinate points, S1 went further to the object stage by encapsulating the process to illustrate the graph object of the relationship between the volume and time. In drawing graphs, S1 made intervals on each axis, where the $x$-axis as $t$ (minute) and the $y$-axis as $V\left(\mathrm{~m}^{3}\right)$. This can be seen from the work of $\mathrm{S} 1$ in drawing graphs and determining the coordinates of the relationship between the volume quantity and the time quantity as shown in Figure 5.

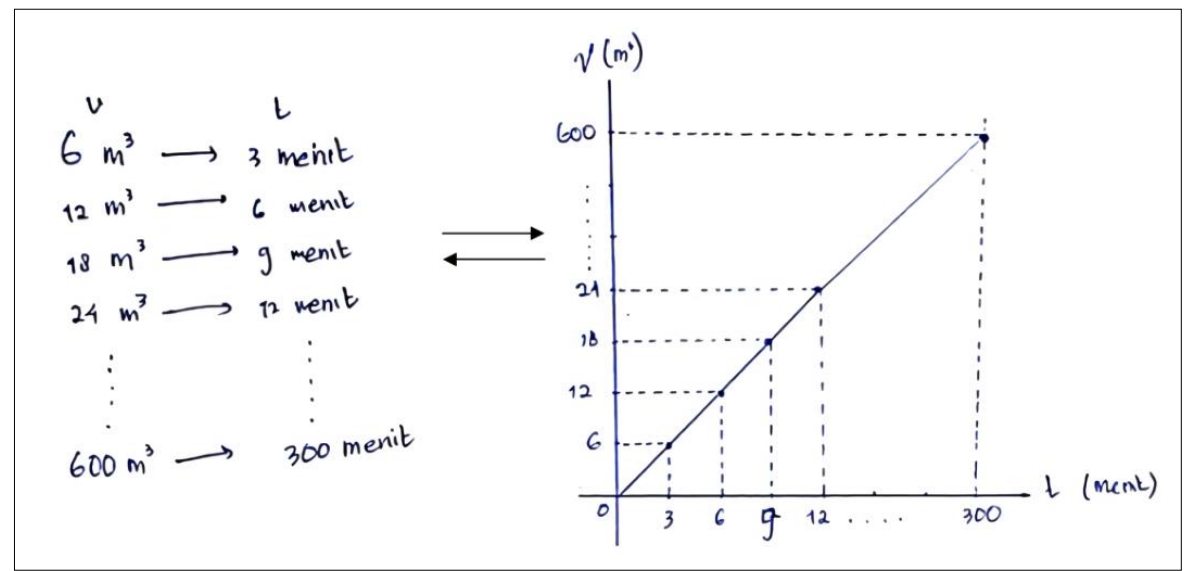

Figure 5. The work of S1 in drawing graphs and determining the coordinates of the relationship between volume and time

S1 believed that the object produced through de-encapsulation to estimate and check the feasibility of the answer to the resulting coordinates. In this process, S1 stated that the interval on the $x$-axis increased 3 times, while the $y$-axis increased 6 times. This shows that S1 communicates quantitative information in terms of coordinating the quantities existing in the mind. This was revealed by S1 when interviewed as in the following interview excerpt.

$\mathrm{R} \quad$ : What kind of chart is that?

$\mathrm{S} 1 \quad$ : Straight-shaped lines. So the volume increase is constant, the time is 3 minutes then the increase is $6 \mathrm{m3}$, so if the interval of $3^{\text {th }}$ minute to $6^{\text {th }}$ minute is equal to 0 to $3^{\text {th }}$ minute (while pointing to the $x$-axis), the same as 0 to $6^{\text {th }}$ minute which is equal to 6th to $12^{\text {th }}$ and so on (while pointing to the y-axis), so the summation is constant.

At the schema stage, S1 interpreted quantitative information and drew conclusions. In this case, $\mathrm{S} 1$ explains that the value of the quantity $t$ (time) was obtained from the volume quantity value divided by 2 , or $t=V / 2$, while the volume was obtained from the time quantity value multiplied by 2 or $V=2 t$. This is seen from the description of the conclusions conveyed by $\mathrm{S} 1$ on the answer sheet as shown in Figure 6. 


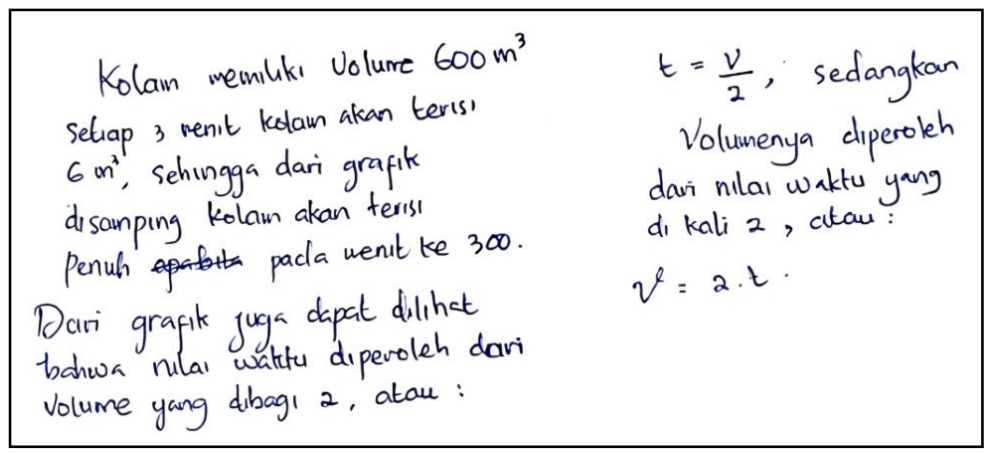

In English:

The pool has volume in the amount of $600 \mathrm{~m}^{3}$, in which every 3 minutes will be filled $6 \mathrm{~m}^{3}$, so that the pool will be fully filled on $300^{\text {th }}$ minute. From the graph, it is also found that time is obtained from the volume value which is divided by 2 or $t=\frac{V}{2}$, whereas the volume is gained by multiplying time value with 2 , or $V=2 t$.

Figure 6. The work of $\mathrm{S} 1$ in concluding the relationship between the volume quantity and the time quantity

This was reinforced by the results of think aloud conducted by S1 as in the following quote.

$\mathrm{S} 1 \quad$ : The pool has a volume of $600 \mathrm{~m}^{3}$, every 3 minutes the pool will be filled with $6 \mathrm{~m}^{3}$, so that the pool will be fully filled when it gained 300 minutes. From the graph, it can also be seen that the time value is obtained from the volume divided by 2, or $t=V / 2$, while the volume is obtained from the time value multiplied with 2, 2 times the time value, or $V=2 t$.

From the exposure and analysis of data that has been done at S1, the thinking process in linking quantities in solving covariation problems occurred at the process stage of APOS. The thinking process in this case was seen as quantitative reasoning. At this stage, S1 connected the volume quantity with the time quantity directly, without calculating using equations to produce other quantities. The scheme of the connecting quantity processes by direct analytic process in solving the covariation problem is presented in Figure 7.

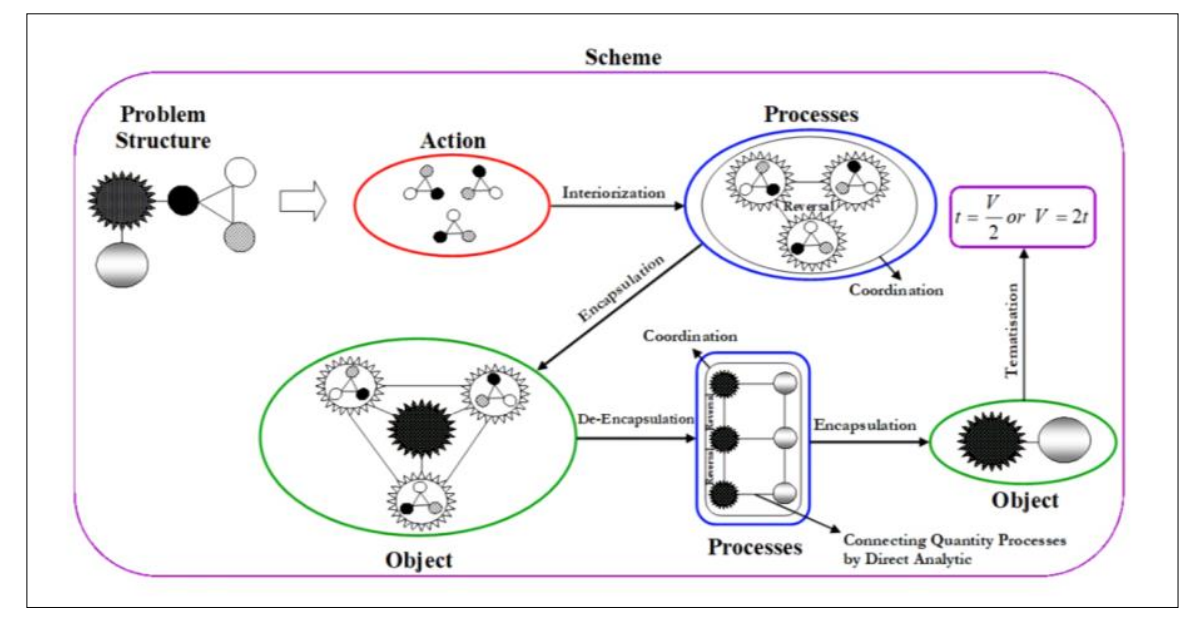

Figure 7. Schema of connecting quantity processes by direct analytic in solving covariation problems 


\section{Second category (S2) data analysis and presentation}

The S2 data presented is the same as in the above S1 data presentation, which describes the structure of thinking in completing the task of solving the covariation problem based on the quantitative reasoning stages with the stages mentioned above. From the work, think aloud recordings, interview recordings, and field notes from S2 were then analyzed together and it referred to the stages of APOS theory (Action, Process, Object, and Schema).

In the action phase, S2 paid attention to the commands in the task, then planned the steps taken to complete the task. As done S1, S2 paid attention to the shape of the pool image and identified the quantities in the pool, those were the length, width, and height of the pool. At the process stage, S2 was conducting coordination by partitioning the shape of the pool into several geometries to make it easier to gain the volume in a different way than that done by S1 which was to partition the pool from the back. S2 also partitioned the pool into three forms of geometry, beam-shaped geometry, trapezoidal prism-shaped geometry, and beam-shaped geometry.

At this stage, S2 planned to find the volume of pool fully filled by searching for the volume of the partitioned pool. In this case, S2 made the symbol of $V_{1}$ as the volume of the first geometry, $V_{2}$ as the volume of second geometry (trapezoidal prism-shaped geometry), $V_{3}$ as the volume of the third space (beam). The process of understanding information and designing solutions to the covariation problems carried out by S2 is shown in the work in Figure 8.

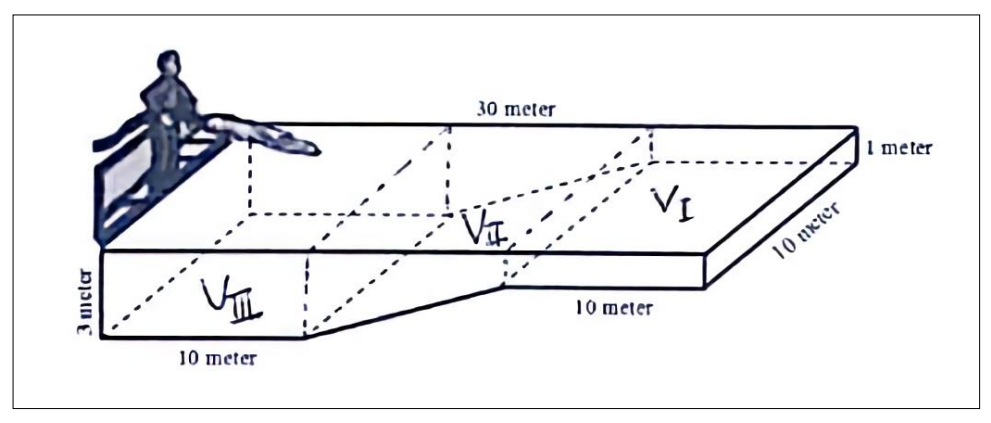

Figure 8. The results of S2 work in understanding and planning solutions to covariation problem

In understanding and planning the solution of this covariation problem is strengthened from the results of think aloud conducted by $\mathrm{S} 2$ as in the following quote.

$\mathrm{S} 2 \quad$ : The picture is divided into three, there is a cube-shaped, $i$ mean a beamshaped (while pointing at the picture from behind), a trapezoidal prism, and also a beam-shaped. Let's say here volume one $\left(V_{1}\right)$, volume two $\left(V_{2}\right)$, and here volume three $\left(V_{3}\right)$.

In the process phase, S2 was doing reversal mechanism by calling back the mathematical method to find the pool volume until it was fully filled by finding the volume of each geometry. The volume of the geometry was searched by using $V=L_{\text {base }} \times h$. Furthermore, it was continued the coordination mechanism of solving the problem by substituting the quantity value of each of the geometrical shape into the predetermined volume formula, so that the first geometric volume was obtained $V_{1}=10 \times 10 \times 1=100 \mathrm{~m}^{3}$, the volume of the 
second geometry was $V_{2}=((3+1) / 2 \times 10) \times 10=200 \mathrm{~m}^{3}$, and the volume of the third geometry was $V_{3}=10 \times 10 \times 3=300 \mathrm{~m}^{3}$. When looking for this volume, there was a coordination process in the process between the three geometries because they were in one unit (pool). While the reversal process occurred when S2 used the same formula in finding the volume of geometry. The process of determining mathematical methods and solving problems is shown in Figure 9.

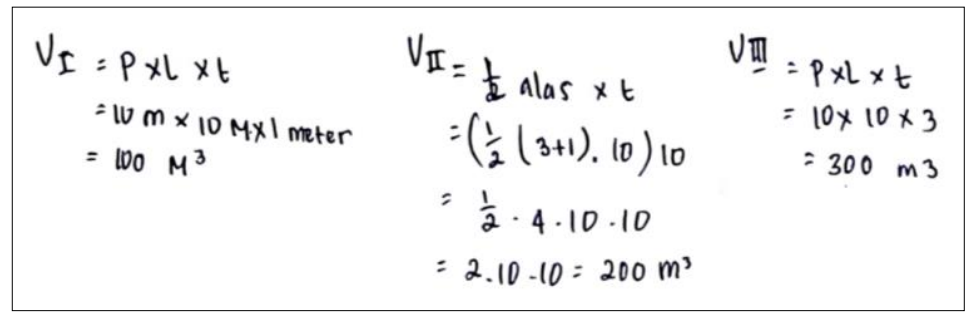

Figure 9. The work of the S2 in determining the mathematical method and solving the problem

This was reinforced from the results of think aloud conducted by $\mathrm{S} 2$ as in the following quote.

S2 : First we look for the first volume $\left(V_{1}\right)$, because here the shape is a beam (while pointing to the first pool) then the first volume formula is the base area $\times$ height $=$ length $\times$ width $\times$ height. The length here is 10 meters $\times$ the width is of 10 meters $\times$ the height is of 1 meter, so $10 \times 10 \times 1=100$ cubic meters. So the first pool volume is 100 cubic meters. Now the second volume, the form of trapezoid, trapezoid volume formula $=1 / 2$ (base area) $\times$ height, base area is $1 / 2 \times$ parallel sides, here there are two parallel lines, here the parallel sides are 3 meters and 1 meter, then the parallel sides are equal to $3 \times 1$, eh, I mean $3+1$ and then multiplied by 10 meters, so $1 / 2(4) \times 10$, so 4 divided by 2 is $2,2 \times 10 \times 10=200$ meters, 200 meters squared. Then the third volume is in the form of a block, so here the length is equal to 10 meters, the width is of 10 meters and the height is of 3 meters, so it is equal to length $\times$ width $\times$ height, which is equal to $10 \times 10 \times$ the height in the number of $3=300$.

The next stage was the process stage, where at this stage, $\mathrm{S} 2$ re-performed the coordination by determining the volume of the fully filled pool, in which adding up the volume of the three existing geometry in the pool. The process included $V_{\text {full }}=V_{1}+V_{2}+V_{3}=100 \mathrm{~m}^{3}+200 \mathrm{~m}^{3}+$ $300 \mathrm{~m}^{3}=600 \mathrm{~m}^{3}$. This is shown from the work of $\mathrm{S} 2$ in Figure 10 and think aloud quotes.

$$
\begin{aligned}
V_{\text {penuth }} & =V_{1}+V_{2}+U_{3} \\
& =100+200+300 \\
& =600 \mathrm{~m}^{3}
\end{aligned}
$$

Figure 10. The work of the $S 2$ in determining the full volume

The think aloud S2 excerpt in adding up the volume of building space to get the pool volume filled. 

300 , so the full volume is equal to 600 cubic meters or 600 cubic meters.

From the volume of the fully filled pool, S2 goes on to determine the time needed to fill the pool until it is fully filled. S2 obtains this time by dividing $V=600 \mathrm{~m}^{3}$ by the discharge of water coming out of the hose that is $6 \mathrm{~m}^{3}$ for 3 minutes. So that this time is obtained for 300 minutes. This is shown by the work of S2 in Figure 11 and from the think aloud transcript.

$$
\omega_{\text {aktu }}=\frac{600 \mathrm{~m}^{3}}{6 \text { meter }} \times 3 \text { menlt }=300 \text { menit }
$$

Figure 11. The S2's work results in determining the time to fill the pool until it is full

Think aloud quotes of S2 in determining the time needed to fill the pool until it is fully charged.

S2 : Then later to find the time needed, the maximum time needed to search until the volume is full, so the formula is equal to the full volume of $600 \mathrm{~m}^{3}$ divided by the discharge of 6 meters and then multiplied by 3 minutes. So the time needed to reach full volume is 300 minutes.

In the next object stage, S2 communicated quantitative information graphically by encapsulating the process by drawing a graph of the relationship between the quantity of volume and the quantity of time. The graph was depicted only the $x$-axis and $y$-axis first before the interval and coordinate points were determined. To complete the graph drawing process, S2 de-encapsulated the graph coordinate points. In determining the coordinate point, S2 made the example $x$ as time and $y$ as the volume and created the equation to do the comparison. First, S2 determined when the pool was fully filled with a ratio of $3 / x=6 / 600$, so a value of $x=300$ minutes was obtained. Then $\mathrm{S} 2$ supposed $\mathrm{y}$ as the volume at a certain time, at a time $=6$ minutes, the comparison to get the volume value was $6 / 300=y / 600$, so that the value of $y=12 \mathrm{~m}^{3}$ was obtained. When the time $=12$ minutes, the volume value was $6 / 300=$ $y / 600$, so that the value of $y=24 \mathrm{~m}^{3}$ was obtained. When making comparison to obtain these coordinate points, the process of coordination occurred because it coordinated the point to point in drawing graphs. Then the reversal process occurred when S2 repeated the same comparison process to determine different coordinate points. The process of determining the coordinate points in drawing graphs carried out by $\mathrm{S} 2$ is shown in Figure 12.

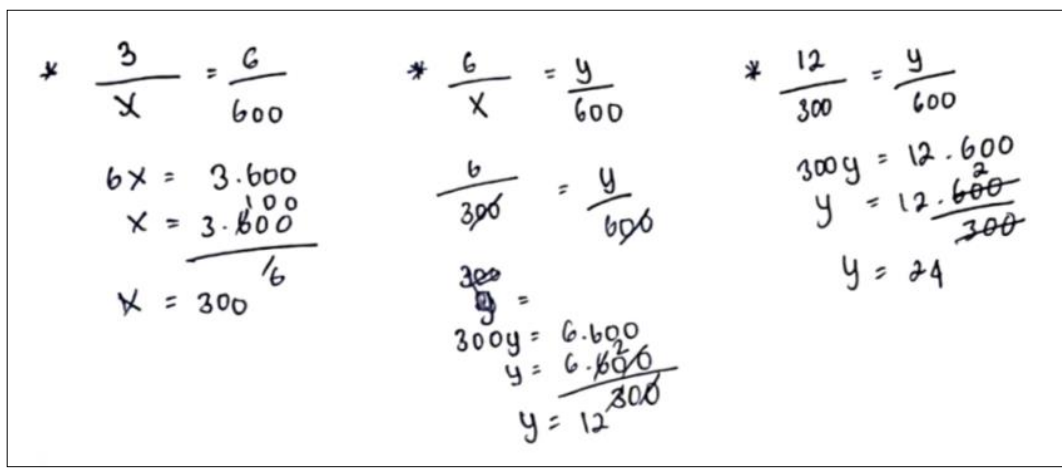

Figure 12. The work of $S 2$ in determining the coordinate points of the relationship between volume and time 
This was reinforced from the results of think aloud conducted by $\mathrm{S} 2$ as in the following quote.

$\mathrm{S} 2 \quad$ : Then look for equality so we know the comparison every time we use it like here (while looking back at solving the problem above), let's say the volume is filled while the time is 3 minutes, considered as $x$, so it's equal to 6 per maximum volume of 600, we're looking for this time maximum, so we use that equation. So $6 x=3 \times 600$, so $x=(3 \times 600) / 6$, this runs out to be the remaining 100, so $x=300$. Proved that the maximum volume is $600 \mathrm{~m}^{3}$, the maximum time is 300 minutes. Suppose we try here 6 minutes, so we try with this equation, time is 6 per maximum time, $x$. Let's say the volume, $y$ per maximum volume of 600 , so here the substitution $6 / 300=y / 600$, so here $300 y$ $=6 \times 600$, so $y=(6 \times 600) / 300$, so $y=12$. So for the 6 minutes time then the volume is $12 \mathrm{~m}^{3}$. Let's say the time is 12 minutes, so we try to use the equation earlier, here the time is 12 minutes per maximum time $x$, so the maximum time was 300 minutes, $y$ is the volume we are looking for within 12 minutes, so let's say the maximum volume / $y$ is 600 , so $300 y=12 \times 600$, so here $y=(12 \times 600) / 300,600 / 300$ remains 2 , so $12 \times 2$, so $y=24$, so for 12 minutes required volume in the amount of $24 \mathrm{~m}^{3}$.

After determining the coordinates, S2 returned to the object stage by encapsulating the process by drawing a graph of the relationship between the volume quantity and the time quantity by determining the $x$-axis as $t$ (minutes) and the $y$-axis as $V\left(\mathrm{~m}^{3}\right)$. Then $\mathrm{S} 2$ made intervals on each axis and determined the coordinates and connected them with a line. The graphic drawing process carried out by $\mathrm{S} 2$ is shown in Figure 13.

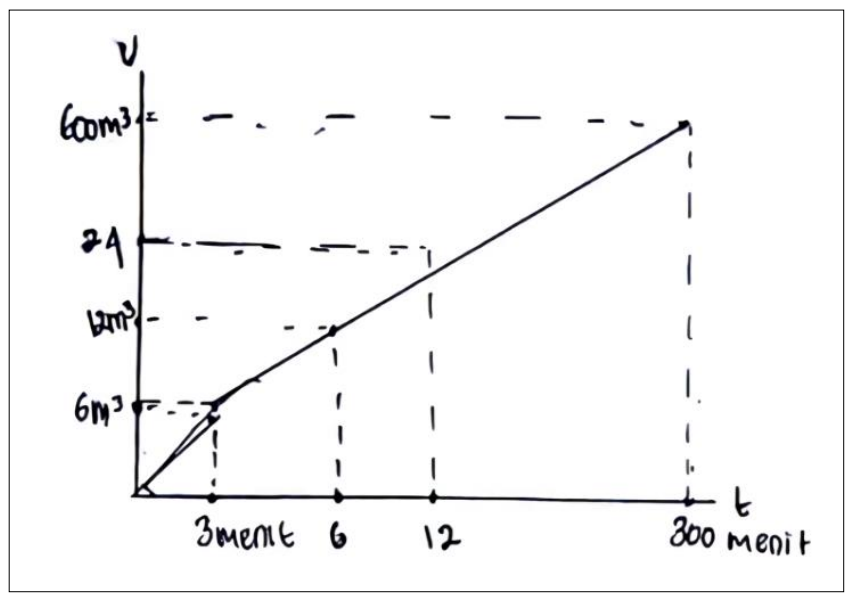

Figure 13. The S2's work in drawing a graph of the relationship of volume quantity to time quantity

In the scheme stage, S2 started by estimating and checking the feasibility of the answers that had been generated, both the process of determining the coordinates and drawing graphs. S2 performed the process of comparing again between volume and time by means of $6 / 3=2$, $12 / 6=2,24 / 12=2,600 / 300=2$, so that the conclusion was: volume was 2 times the time or $y=2 x$. At this stage, $\mathrm{S} 2$ also interpreted quantitative information and drew a picture of the relationship of volume quantity and time quantity by making the conclusion that the greater the volume of a geometry, the more time it needs to fill in the pool, and vice versa. This can be seen from the work of S2 as shown in Figure 14, Figure 15 and think aloud transcripts. 


\section{$y=2 x$}

Figure 14. The work of $S 1$ in determine the equation

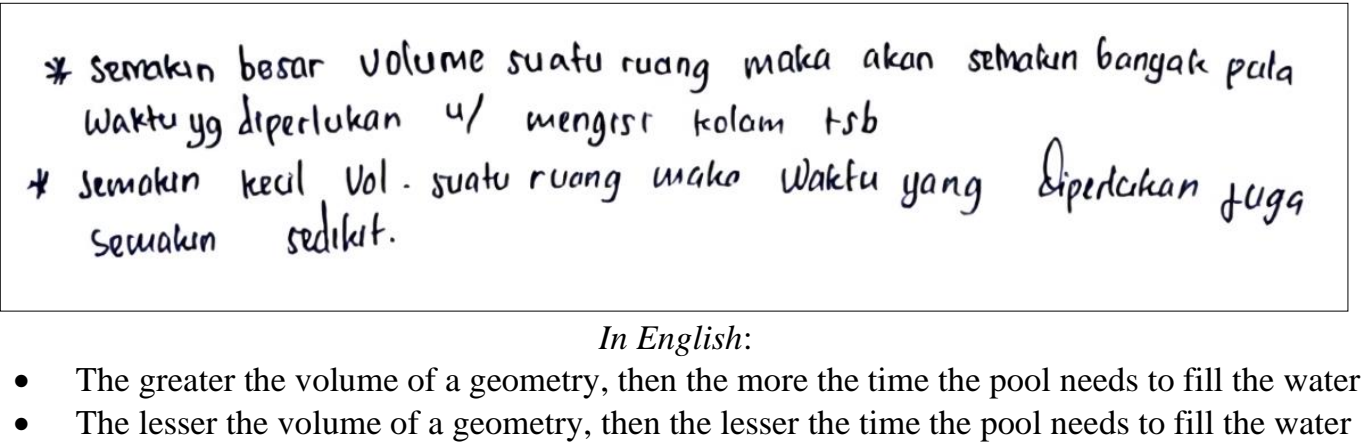

Figure 15. The S2's work in concluding a relationship between volume and time

The think aloud excerpt of S2 in adding up the volume of geometry to get the pool volume filled.

$\mathrm{S} 2 \quad$ : So the time needed for a $24 \mathrm{~m}^{3}$ volume is 12 minutes. So from the previous comparison, each volume requires a time ratio of $y=2 x$. So the comparison is $y=2 x .12 / 24$ equals $2,12 / 6=2,6 / 3=2$. So the maximum volume is also $600 / 300=2$. So the ratio of each time and volume is equal to $y=2 x$. So the volume is the same as twice the time.

Then to see the concept of thinking of S2 about the resulting graph, researchers asked the shape of the resulting graph. S2 concluded that the resulting graph was a graph of straight graph equation or graph with linear equation. As seen from the following interview transcript.

$\mathrm{R} \quad$ : What is this equation? (while pointing to the equation that the subject gets).

$\mathrm{S} 2 \quad$ : Equation ... for this calculation (while showing the graph in the picture).

$\mathrm{R} \quad$ : What are these equations?

S2 : Equation ...?? ?? ? not a quadratic equation, but ...

$\mathrm{R} \quad$ : What equation do you have?

S2 : The equation of these two variables.

$\mathrm{S} 2$ : ooh, linear equation, linear equation of two variables.

$\mathrm{R} \quad$ : If the linear equation tends to produce results, what is the shape of the graph?

S2 : It's a straight line, so it's straight up like that.

From the presentation and analysis of data that had been done at $S 2$, the thinking process in linking quantities in solving covariation problems occurred at the same stage as carried out by $\mathrm{S} 1$, that was at the process stage of APOS. However, the process of linking quantities by S2 was carried out using an intermediary equation. In this case, S2 connected the quantity of volume with the quantity of time analytically by using equation to make comparisons. The schema of the connecting quantity processes by equation analytic process in solving covariation problems is presented in Figure 16. 


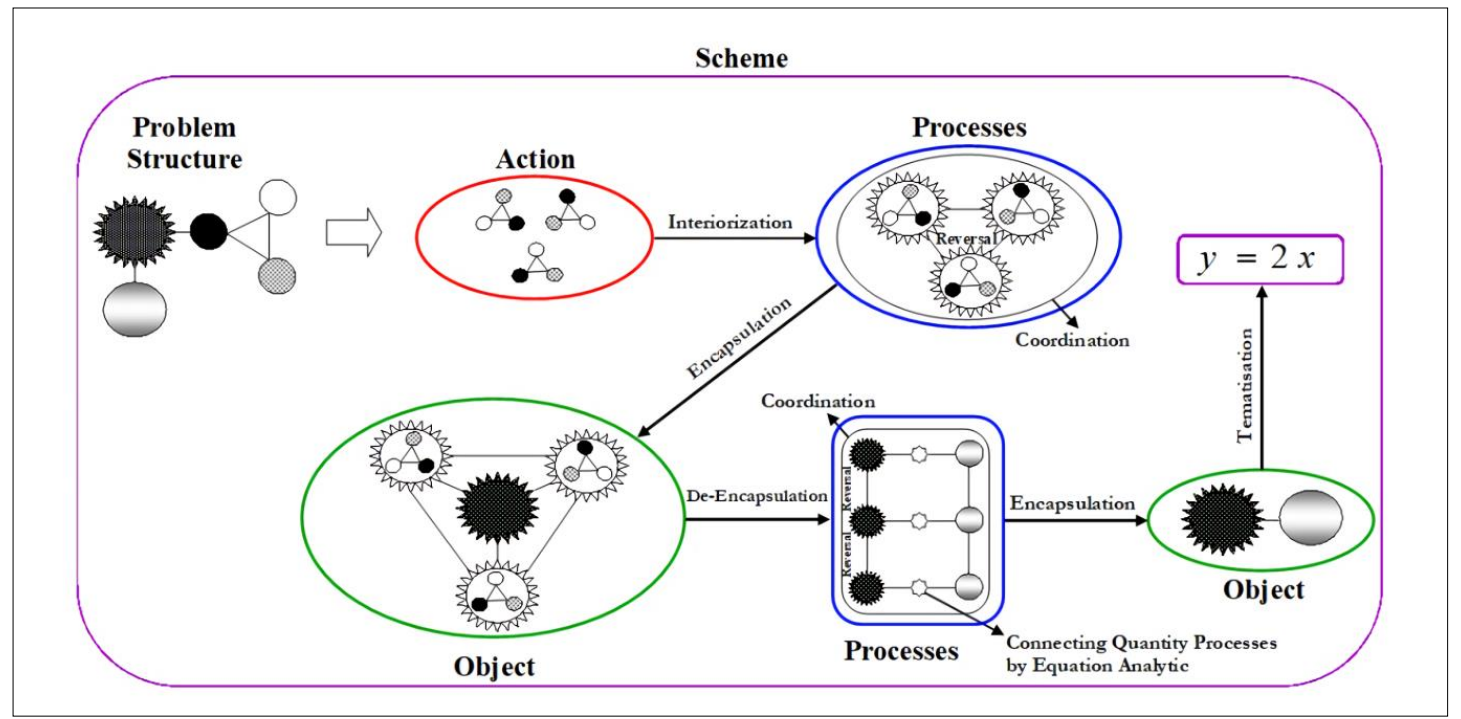

Figure 16. Schema of connecting quantity processes by equation analytic schema in solving covariation problems

\section{Discussion}

The students' thinking process connects quantities in solving the covariation problem that occurs at the process stage of APOS. In which students express the quantities relationship in the internal mind, so that it is possible to imagine and transform without having to explicitly execute each step (Dubinsky et al., 2005).

From the presentation and data analysis, it showed two different thinking processes carried out by the subject in connecting the quantity to solve the problem in the form of covariation. The first thinking process was to link quantity in solving covariation problems done directly or without conducting in-depth analysis using equations. The second thinking process was to relate quantities to the solution of the covariation problem by using an intermediary process that was done by using equations to produce other quantities of their changes. The problem solving process shown from these two processes uses a mathematical approach with arithmetic and algebra (Dwyer et al., 2003) and thinking inductively and deductively (Carroll, 1993; Syarifuddin et al., 2019a).

The problem solving process is a mathematical process that can be represented in graphical form by coordinating the quantity relationship as the x-axis and the y-axis in the form of a Cartesian graph. In the coordination relationship between the $\mathrm{x}$-axis and the $\mathrm{y}$-axis, changes in the increase in the value of a quantity are followed by an increase in the value of a quantity (Ayalon et al., 2015, 2016; Carlson et al., 2002; Ellis, 2007; Heather Lynn Johnson, 2015; Stalvey \& Vidakovic, 2015; Yemen-Karpuzcu et al., 2017) . In this case, the graph produced by students is a graph with a constant increase in change and it forms a linear graph. Therefore, the comparison process carried out by students can produce equations such as $t=$ $2 \mathrm{~V}$ or $\mathrm{x}=2 \mathrm{y}$. In this case, the equation is a linear function (Ellis, 2007).

Thinking process shown by the student was reasoning that can be seen from the problem solving process and can be explored systematically (Rosdiana, Budayasa, \& Lukito, 2019). Therefore, the thinking process was perceived as quantitative reasoning because it connected quantities and saw the relationship to each other in getting solutions. When students use quantitative reasoning, students think with quantities and relations of quantities (Ellis, 2011; 
Kabael \& Akin, 2018). In finding solutions to covariation problems, students applied the problem-solving process through structured and measurable reasoning. In this condition a quantitative reasoning student utilized problem solving approach focusing to quantities, calculating, and applying formula (Kabael \& Akin, 2018).

\section{Conclusion}

From the explanation and data analysis and discussion, in general this research yields the conclusion that the students' thinking process connected quantities in covariation problem solving was done by linking quantities that changed along with changes in other quantities to form new quantities based on quantitative operations. In this case, there were two thinking processes that can be concluded, namely connecting quantity processes by direct analytic and connecting quantity processes by equation analytic. Connecting quantity processes by direct analytic is the process of connecting quantities carried out directly without using equations and expressed internally in the mind. Whereas connecting quantity processes by equation analytic is a process of linking quantities carried out by students through an intermediary process by using equations to produce other quantities of changes in quantity. This process was expressed externally with comparative analysis using equations. The students' thinking process on this covariation problem was quantitative reasoning and produced the concept of linear functions.

Recommendations from the results of this study, first, in the learning process teachers should arrange tasks that can arouse students' thinking processes, especially in connecting the quantities and drawing graphics. Secondly, this research is only on solving covariation problems with linear quantities relationships or linear functions. For further research, it can conduct research on students' thinking processes on covariation problems with non-linear quantities relations, for example the quantities relationships that produce parabolic charts and so on.

\section{Acknowledgements}

The researchers would like to express their gratitude to the Ministry of the Research, Technology, and Higher Education of Republic of Indonesia, LPDP Indonesia, Universitas Negeri Malang, and STKIP Bima.

\section{References}

Arnon, I., Dubinksy, E., Roa-Fuentes, S., Weller, K., Cottrill, J., Oktaç, A., et al. (2014). APOS theory: A framework for research and curriculum development in mathematics education. Springer.

Ayalon, M., Watson, A., \& Lerman, S. (2015). Functions represented as linear sequential data: relationships between presentation and student responses. Educational Studies in Mathematics, 90(3), 321-339. https://doi.org/10.1007/s10649-015-9628-9

Ayalon, M., Watson, A., \& Lerman, S. (2016). Reasoning about variables in 11 to 18 year olds: informal, schooled and formal expression in learning about functions. Mathematics Education Research Journal, 28(3), 379-404. https://doi.org/10.1007/s13394-016-0171-5

Brown, C. (2007). Cognitive psychology. In Cognitive Psychology. SAGE Publications India Pvt Ltd. https://doi.org/10.4135/9781446212967 
Burns-Childers, A., \& Vidakovic, D. (2018). Calculus students' understanding of the vertex of the quadratic function in relation to the concept of derivative. International Journal of Mathematical Education in Science and Technology, 49(5), 660-679. https://doi.org/10.1080/0020739X.2017.1409367

Bybee, R. W. (1982). Piaget for Educators. Charles E Merri Publising. co Colombus Ohio.

Carlson, M. (1998). A cross-sectional investigation of the development of the function concept (pp. 114-162). Research in collegiate mathematics education. III. CBMS issues in mathematics education. https://doi.org/10.1090/cbmath/007/04

Carlson, M., Jacobs, S., Coe, E., Larsen, S., \& Hsu, E. (2002). Applying covariational reasoning while modeling dynamic events: A framework and a study. Journal for Research in Mathematics Education, 33(5), 352-378. https://doi.org/10.2307/4149958

Carroll, J. B. (1993). Human cognitive abilities: A survey of factor-analytic studies. England: Cambridge University Press.

Clement, J. (1989). The concept of variation and misconceptions in cartesian graphing. Focus on Learning Problems in Mathematics, 11(1-2), 77-87.

Confrey, J., \& Smith, E. (1995). Splitting, Covariation, and Their Role in the Development of Exponential Functions. Journal for Research in Mathematics Education, 26, 66-86. https://doi.org/10.2307/749228

Copi, I. M. (1978). Introduction to Logic. New York: Macmillan.

Corbin, J., \& Strauss, A. (2012). Basics of Qualitative Research (3rd ed.): Techniques and Procedures for Developing Grounded Theory. In Basics of Qualitative Research (3rd ed.): Techniques and Procedures for Developing Grounded Theory. London: Sage Publications. https://doi.org/10.4135/9781452230153

Creswell, J. W. (2012). Educational research: Planning, conducting, and evaluating quantitative and qualitative research. In Educational Research. Thousand Oaks, CA: Sage. https://doi.org/10.1017/CBO9781107415324.004

Dubinsky, E., \& Mcdonald, M. A. (2011). APOS: A Constructivist Theory of Learning in Undergraduate Mathematics Education Research. In D. Holton et al. (Ed.), The Teaching and Learning of Mathematics at University Level (pp. 273-280). An ICMI Study. Kluwer Academic Publisher. https://doi.org/10.1007/0-306-47231-7_25

Dubinsky, E. (1991). Reflective abstraction in advanced mathematical thinking. In D. O. Tall (Ed.), Advanced mathematical thinking (pp. 95-123). Dordrecht: Kluwer.

Dubinsky, E. (2001). Using a theory of learning in college mathematics courses. MSOR Connections, 1(2), 10-15.

Dubinsky, E., Weller, K., McDonald, M. A., \& Brown, A. (2005). Some historical issues and paradoxes regarding the concept of infinity: An APOS-based analysis: Part 1. Educational Studies in Mathematics, 58(3), 335-359. https://doi.org/10.1007/s10649005-2531-z

Dwyer, C. A., Gallagher, A., Levin, J., \& Morley, M. E. (2003). WHAT IS QUANTITATIVE REASONING? DEFINING THE CONSTRUCT FOR ASSESSMENT PURPOSES. ETS Research Report Series. https://doi.org/10.1002/j.2333-8504.2003.tb01922.x

Ellis, A. B. (2007). Connections between generalizing and justifying: Students' reasoning with linear relationships. Journal for Research in Mathematics Education, 38(3), 194229.

Ellis, A. B. (2011). Algebra in the Middle School: Developing Functional Relationships Through Quantitative Reasoning. In Cai Jinfa \& E. and Knuth (Ed.), Early Algebraization: A Global Dialogue from Multiple Perspectives (pp. 215-238). Berlin, Heidelberg: Springer Berlin Heidelberg. https://doi.org/10.1007/978-3-642-177354_13 
Johnson, Heather L. (2012). Reasoning about variation in the intensity of change in covarying quantities involved in rate of change. Journal of Mathematical Behavior, 31(3), 313330. https://doi.org/10.1016/j.jmathb.2012.01.001

Johnson, Heather Lynn. (2015). Secondary Students' Quantification of Ratio and Rate: A Framework for Reasoning about Change in Covarying Quantities. Mathematical Thinking and Learning. https://doi.org/10.1080/10986065.2015.981946

Kabael, T., \& Akin, A. (2018). Prospective Middle-School Mathematics Teachers' Quantitative Reasoning and Their Support for Students' Quantitative Reasoning. International Journal of Research in Education and Science, 4(1), 178-197. https://doi.org/10.21890/ijres.383126

Kaput, J. (1995). A research base for algebra reform: Does one exist. In \& G. M. M. D. Owens, M. Reed (Ed.), Proceedings of the 17th Annual Meeting of the North American Chapter of the International Group for the Psychology of Mathematics Education (pp. 71-94). Columbus, OH: The ERIC Clearinghouse for Science, Mathematics, and Environmental Education.

Köklü, Ö. (2007). An investigation of college students' covariational reasoning. In Doctoral dissertation. Florida State University.

Krulik, S., Rudnick, J. A., \& Milou, E. (2003). Teaching mathematics in middle school: A practical guide (Allyn and Bacon (ed.)). Boston.

Moore, K. C. (2014). Quantitative reasoning and the sine function: The case of Zac. Journal for Research in Mathematics Education, 45(1), 102-138. https://doi.org/10.5951/jresematheduc.45.1.0102

Moore, K. C., \& Carlson, M. P. (2012). Students' images of problem contexts when solving applied problems. Journal of Mathematical Behavior, 31(1), 48-59. https://doi.org/10.1016/j.jmathb.2011.09.001

NCTM. (2000). Principle and Standards for Schools Mathematics. Resto, VA.

Parraguez, M., \& Oktaç, A. (2010). Construction of the vector space concept from the viewpoint of APOS theory. Linear Algebra and its Applications, 432(8), 2112-2124.

Ramful, A. (2009). Reversible Reasoning in Multiplicative Situations: Conceptual Analysis, Affordances and Constraints. Doctoral dissertation, University of Georgia.

Rosdiana, Budayasa, I. K., \& Lukito, A. (2019). Pre-Service Primary School Teachers' Mathematical Reasoning Skills from Gender Perspectives: A Case Study. Journal for the Education of Gifted Young Scientists, 7(4), 1107-1122. https://doi.org/10.17478/jegys.620234

Saldanha, L. A., \& Thompson, P. W. (1998). Re-thinking Covariation from a Quantitative Perspective: Simultaneous Continuous Variation. In K. N. \& L. S. S. B. Berensah, K. R. Dawkings, M. Blanton, W. N. Coulombe, J. Kolb (Ed.), Proceedings of the Annual Meeting of the Psychology of Mathematics Education - North America (pp. 298-303). Columbus, OH: ERIC.

Slavit, D. (1997). An alternate route to the reification of function. Educational Studies in Mathematics, 33(3), 259-281. https://doi.org/10.1023/A:1002937032215

Smith, J., \& Thompson, P. (2007). Quantitative Reasoning and the Development of Algebraic Reasoning. In \& M. L. B. J. J. Kaput, D. W. Carraher (Ed.), Algebra in the early grades (pp. 95-132). New York: Lawrence Erlbaum.

Stalvey, H. E., \& Vidakovic, D. (2015). Students' reasoning about relationships between variables in a real-world problem. Journal of Mathematical Behavior, 40, 192-210. https://doi.org/10.1016/j.jmathb.2015.08.002

Steffe, L. P., \& Olive, J. (2010). Children's fractional knowledge. USA: Springer Science \& Business Media. https://doi.org/10.1007/978-1-4419-0591-8 
Sümen, Ö. Ö., \& Çalışıcı, H. (2016). The Relationships Between Preservice Teachers' Mathematical Literacy Self Efficacy Beliefs, Metacognitive Awareness And Problem Solving Skills. Participatory Educational Research, 3(5), 11-19. https://doi.org/10.17275/per.16.spi.2.2

Syarifuddin, Nusantara, T., Qohar, A., \& Muksar, M. (2019a). Quantitative reasoning process in mathematics problem solving: A case on covariation problems reviewed from Apos theory. Universal Journal of Educational Research, 7(10), 2133-2142. https://doi.org/10.13189/ujer.2019.071011

Syarifuddin, Nusantara, T., Qohar, A., \& Muksar, M. (2019b). The Identification Difficulty of Quantitative Reasoning Process toward the Calculus Students' Covariation Problem. Journal of Physics: Conference Series, 1254(1). https://doi.org/10.1088/17426596/1254/1/012075

Thompson, P. W. (1993). Quantitative reasoning, complexity, and additive structures. Educational Studies in Mathematics, 25(3), 165-208. https://doi.org/10.1007/BF01273861

Thompson, P. W. (1994). The development of the concept of speed and its relationship to concepts of rate. In The development of multiplicative reasoning in the learning of mathematics (pp. 179-234).

Weber Eric, Amy Ellis, Torrey Kulow, \& Zekiye Ozgur. (2014). Six Principles for Quantitative Reasoning and Modeling. The Mathematics Teacher, 108(1), 24-30. https://doi.org/10.5951/mathteacher.108.1.0024

Yemen-Karpuzcu, S., Ulusoy, F., \& Işıksal-Bostan, M. (2017). Prospective Middle School Mathematics Teachers' Covariational Reasoning for Interpreting Dynamic Events During Peer Interactions. International Journal of Science and Mathematics Education, 15(1), 89-108. https://doi.org/10.1007/s10763-015-9668-8 